\title{
A Sequence of Phase Transformations and Phases in NiCoFeCrGa High Entropy Alloy
}

\author{
Ádám Vida ${ }^{1}$, János Lábár ${ }^{2,3}{ }^{\mathbb{D}}$, Zoltán Dankházi ${ }^{2}$, Zsolt Maksa ${ }^{2}$, Dávid Molnár ${ }^{4,5} \mathbb{D}^{\text {, Lajos K. Varga }}{ }^{6}$, \\ Szilvia Kalácska ${ }^{7}$, Márk Windisch ${ }^{1}$, Gabriella Huhn ${ }^{2}$ and Nguyen Q. Chinh ${ }^{2, *(D)}$
}

1 Department of Industrial Materials Technology, Bay Zoltán Nonprofit Ltd. for Applied Research, Kondorfa u.1., H-1116 Budapest, Hungary; Adam.Vida@bayzoltan.hu (Á.V.);

Mark.Windisch@bayzoltan.hu (M.W.)

2 Department of Materials Physics, Eötvös Loránd University, P.O.B. 32, H-1518 Budapest, Hungary; labar.janos@ek-cer.hu (J.L.); zoltan.dankhazi@ttk.elte.hu (Z.D.); zs.maksa@gmail.com (Z.M.); huhnandrasne@gmail.com (G.H.)

3 Thin Films Physics Laboratory, Centre of Energy Research, Konkoly-Thege u. 29-33, H-1121 Budapest, Hungary

4 Materials Science Group, Dalarna University, SE-791-88 Falun, Sweden; mdi@du.se

5 Applied Materials Physics, Department of Materials Science and Engineering, Royal Institute of Technology, SE-100-44 Stockholm, Sweden

6 Institute of Solid State Physics and Optics, Wigner Research Center for Physics, H-1121 Budapest, Konkoly-Thege u. 29-33, Hungary; varga@szfki.hu

7 Empa, Swiss Federal Laboratories for Materials Science and Technology, Laboratory of Mechanics of

check for updates

Citation: Vida, Á.; Lábár, J.; Dankházi, Z.; Maksa, Z.; Molnár, D.; Varga, L.K.; Kalácska, S.; Windisch, M.; Huhn, G.; Chinh, N.Q. A Sequence of Phase Transformations and Phases in NiCoFeCrGa High Entropy Alloy. Materials 2021, 14, 1076. https://doi.org/10.3390/ ma14051076

Academic Editors: S. Joseph Poon and Jian-Zhong Jiang

Received: 31 December 2020

Accepted: 22 February 2021

Published: 25 February 2021

Publisher's Note: MDPI stays neutral with regard to jurisdictional claims in published maps and institutional affiliations.

Copyright: (c) 2021 by the authors. Licensee MDPI, Basel, Switzerland. This article is an open access article distributed under the terms and conditions of the Creative Commons Attribution (CC BY) license (https:/ / creativecommons.org/licenses/by/ $4.0 /)$.

\section{Materials and Nanostructures, Feuerwerkerstrasse 39, 3602 Thun, Switzerland; szilvia.kalacska@empa.ch}

* Correspondence: chinh@metal.elte.hu; Tel.: +36-1-372-2845

Abstract: The present investigation is directed to phase transitions in the equimolar NiCoFeCrGa high entropy alloy, which is a mixture of face-centered cubic (FCC) and body-centered cubic (BCC) crystalline phases. The microstructure of the samples was investigated by using scanning electron microscopy (SEM), time-of-flight secondary ion mass spectroscopy (TOF-SIMS), transmission electron microscopy-based energy-dispersive spectroscopy (EDS) and electron energy loss spectroscopy (EELS), as well as X-ray diffraction (XRD) measurements. Based on the phases observed in different temperature ranges, a sequence of the phase transitions can be established, showing that in a realistic process, when freely cooling the sample with the furnace from high to room temperature, a microstructure having spinodal-like decomposition can also be expected. The elemental mapping and magnetic behaviors of this decomposed structure are also studied.

Keywords: NiCoFeCrGa high entropy alloys; phase transformations; multiphase; spinodal decomposition; magnetic behavior

\section{Introduction}

Being multicomponent alloys, the microstructure of the high entropy alloys (HEAs)in principle - could be highly variable. Surprisingly, however, most of the previous investigations have shown that the structure of the HEAs is quite simple: the mixture of face-centered cubic (FCC) and body-centered cubic (BCC) or hexagonal close-packed (HCP) lattices. There are no, or just a very few, intermetallic phases in the microstructure of HEAs. Based on the high number of elements, one might think that there should exist more likely and unlikely atomic groups due to the enthalpies of forming, but the system remained in a solid solution state, at least it seemed so for a long time [1-3]. In addition, it should be mentioned that the cooling rate may have a significant effect on the microstructure. It has been shown in the case of the NiCoFeCrGa high entropy alloy $[4,5]$ that the cooling rate influences both the composition of the two (FCC and BCC) phase-components and the ratio of their volume fractions. 
Considering the high number of possible alloying combinations, the high entropy stabilization is believed to be the key feature of the HEAs. Accordingly, many papers were dealing with the question of entropy from the beginning [6-8] and also in the later years [9-17]. The later publications were mainly focusing on the phase stability of singlephase alloys; therefore, the investigations were carried out after applying the right heat treatments. From the discussions of these papers, some conclusions can be drawn: (i) the ascast state should be considered as metastable, and (ii) only very few alloys show resistance against heat treatments and remain single-phase.

The four-component, equimolar $\mathrm{NiCoFeCr}$, often called the first-and-base HEA, has been the topic of recent theoretical and experimental works [3,18-23]. Furthermore, the systematic investigation of the effect of the sp. element additions is also well studied in the literature [24-27].

Without adding any doping elements, the structure of NiCoFeCr base alloy is a singlephase FCC in a paramagnetic state at room temperature. It has been shown that with the addition of $\mathrm{Ga}$, the single-phase base system turned into a duplex in the equimolar $\mathrm{NiCoFeCrGa}$ high entropy alloy [26]. The role of phase mixing in this alloy was then studied and analyzed by tracking the mechanical and structural properties of the alloy obtained after different heat-treatments [4]. Together with the microstructural investigation, it was also observed that the $\mathrm{NiCoFeCrGa}$ system shows anomalous thermal expansion, which can be explained by the phase transition from ferromagnetic BCC to paramagnetic FCC in the microstructure of the alloy [27].

Continuing previous works, the goal of the present study was to follow the evolution of phase structures in the NiCoFeCrGa HEA during targeted heat treatments. In this work, we report for the first time on a sequence of phase transitions and on the spinodal-like decomposition in this high entropy alloy.

\section{Materials and Methods}

\subsection{Processing of the Samples}

The investigated alloys were prepared from pure metals (99.99\%) with high precision in Wigner Research Center for Physics, Budapest Hungary. Induction melting in a cold copper mold with an inert atmosphere was used to prepare the specimens. Every ingot was at least five times re-melted to help the mixing. The typical mass of the specimen was around $25 \mathrm{~g}$.

The specimen was first ground to obtain a flat surface, then mechanically polished by $9 \mu \mathrm{m}, 6 \mu \mathrm{m}$ and $1 \mu \mathrm{m}$ particle size diamond suspensions. The last step of the polishing was done by colloidal silica (Struers OP-S and OP-U). The heat treatments were performed in a tube furnace under Ar gas (99.95\% purity) protection. Separate samples were heat-treated for $1 \mathrm{~h}$ at different temperatures in the range between 560 and $1273 \mathrm{~K}$ and then quenched into the water at room temperature (WQ). The heating rate was set to $10 \mathrm{~K} / \mathrm{min}$. An initial sample was treated at $1150 \mathrm{~K}$ for $1 \mathrm{~h}$ and then slowly cooled (SC) with the furnace. Here we note that the cooling speed of the as-cast (AC) sample during the casting was around $50 \mathrm{~K} / \mathrm{s}$. Furthermore, the cooling speed of WQ and SC samples was around $10^{3}$ and $10^{-1} \mathrm{~K} / \mathrm{s}$, respectively [4].

\subsection{Microstructure Characterization Techniques}

The microstructural investigation and chemical analysis were carried out with scanning electron microscopes (SEM) in multifunctional FEI Quanta 3D equipment (Thermo Fischer Scientific, Waltham, MA, USA) and a Zeiss ULTRA 55 (Zeiss, Jena, Germany). Electron backscattered diffraction (EBSD) was also carried out with Quanta 3D.

For the chemical surface analysis, a Tescan Lyra3 FEG-SEM (TESCAN, Brno, Czech Republic) was used, equipped with a time-of-flight secondary ion mass spectroscopy (TOF-SIMS, TOFWERK AG. Thun, Switzerland). This focused ion beam (FIB) based method [28-30] uses the $\mathrm{Ga}^{+}$impacting ions to sputter the sample locally while collecting and selecting the sputtered ions based on their mass. TOF-SIMS has the advan- 
tage of excellent lateral and depth resolution, as the sputtered ions originate from the few top atomic layers [31,32]. However, the sputtering speed depends on the chemical and crystallographic composition of the sample; therefore, surface roughness analysis after TOF-SIMS measurement can give qualitative information about the sputtering speeds of the analyzed structures [33]. TOF-SIMS measurements were concluded using an ion beam of $30 \mathrm{kV}, 40-160 \mathrm{pA}$ combined with a gas injection system (GIS) operating with fluorine gas. The fluorine gas was applied to increase ionization probability to enhance secondary ion signals during TOF-SIMS analysis [34]. Secondary electron images were recorded before and after FIB sputtering with a $20 \mathrm{kV}$ electron beam at high contrast conditions.

The $300 \mathrm{keV}$ transmission electron microscopy (TEM) was performed on a JEOL 3010 (JEOL, Tokyo, Japan), equipped with an electron energy loss spectrometer (EELS). During the $\mathrm{Cr}$ mapping, a Gatan GIF Tridiem energy-filtered mode was applied. This mode is called energy-filtered transmission electron microscopy (EFTEM).

Thermal analysis was performed with a differential thermal analyzer (DTA, SETARAM SetSys, KEP Technologies, Mougins, France) from room temperature to $1573 \mathrm{~K}\left(1300{ }^{\circ} \mathrm{C}\right)$ at a heating rate of $10 \mathrm{~K} / \mathrm{min}$ in Ar atmosphere. The sample holder was alumina, which was first heated empty to determine the baseline.

The local composition was further determined by using auger electron spectroscopy (ES, Physical Electronics, Chanhassen, Minnesota) technique on a PHI 700 xi. Data were collected using $20 \mathrm{kV}$ accelerating voltage and $10 \mathrm{nA}$ beam current.

The phase compositions were investigated by $X$-ray diffraction (XRD) using a Philips Xpert $\theta-2 \theta$ powder diffractometer (Phillips, Amsterdam, Netherlands) with $\mathrm{CuK} \alpha$ radiation (wavelength: $\lambda=0.15418 \mathrm{~nm}$ ). The pattern was collected using a tube voltage of $40 \mathrm{kV}$ and tube current of $30 \mathrm{~mA}$. The lattice parameter was determined by extrapolating the lattice parameters obtained from the different reflections to the diffraction angle of $2 \theta=180^{\circ}$ using the Nelson-Riley method [34].

\subsection{Magnetic Measurements}

Magnetic force microscopy (MFM) was used to investigate the local magnetic properties of the samples. The phase characteristic of the cantilever's vibration was detected during the MFM measurements carried out by using a Solver Pro NT-MDT atomic force microscope (AFM, NT-NDT, Moscow, Russia). The AFM topography and MFM imaging were performed simultaneously in the same area of the sample by using the two-pass technique. The tip was lifted above the surface of the sample by a distance of about $60 \mathrm{~nm}$ during the MFM measurement. For the dynamic detection mode, the cantilever was vibrating with its resonant frequency $(85 \mathrm{kHz})$, and the phase portion may be modulated by the magnetic forces emerging from the sample. The applied magnetic tips were microfabricated Si cantilevers with a pyramidal tip coated with magnetic $\mathrm{Co}-\mathrm{Cr}$ thin film having $40 \mathrm{~nm}$ thickness.

\section{Results and Discussion}

\subsection{General Observations}

Figure 1 shows the differential thermal analysis (DTA) thermogram of the initial AC sample. Considering the main processes, except for the multistep melting of the complex system (marked as region D), visible phase-transitions can be expected in the two exothermic regions $C$ and $B$ at 1000-1200 and 900-1000 K temperature ranges, respectively. It has been shown before that the change of heat-flow observed in region $\mathrm{A}$ is related to the surrounding of the Curie point of this alloy [4]. The average melting temperature, $T_{m}-$ estimated by the concentration weighted average rule- of this equimolar $\mathrm{NiCoFeCrGa}$ sample was found to be $1547 \mathrm{~K}$, which is in good accordance with the experimentally measured value. 


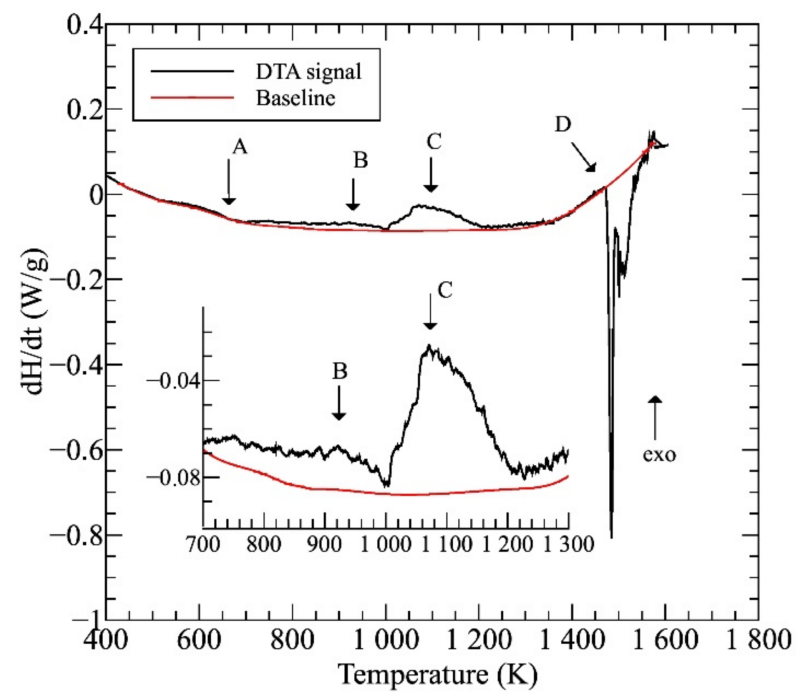

Figure 1. The differential thermal analysis (DTA) thermogram taken on the initial (AC) sample.

As mentioned above, in order to study the possible microstructures and the evolution of the phases, the initial (AC) samples were heat-treated for $1 \mathrm{~h}$ at different temperatures and then quenched into the water at room temperature (WQ). An initial sample was treated at $1150 \mathrm{~K}$ and then slowly cooled with the furnace (SC).

Typical microstructures of the initial (as-cast, AC) and the WQ samples can be seen in the SEM images of Figure 2.
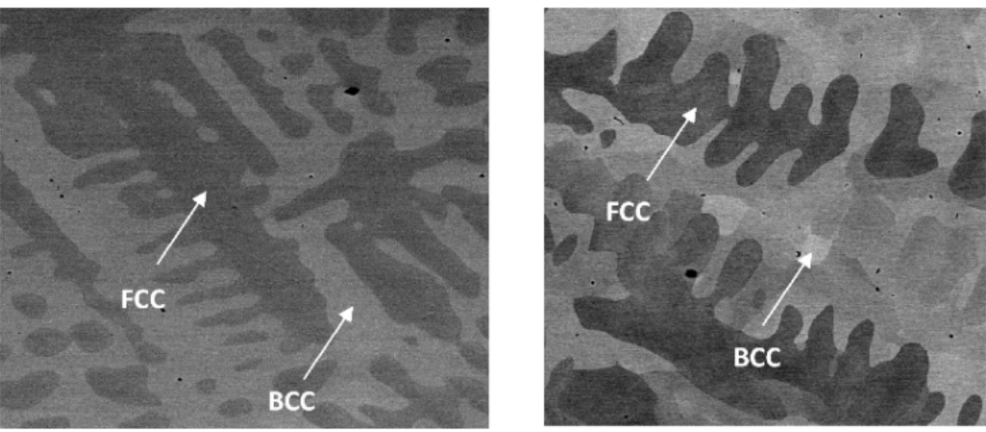

a)

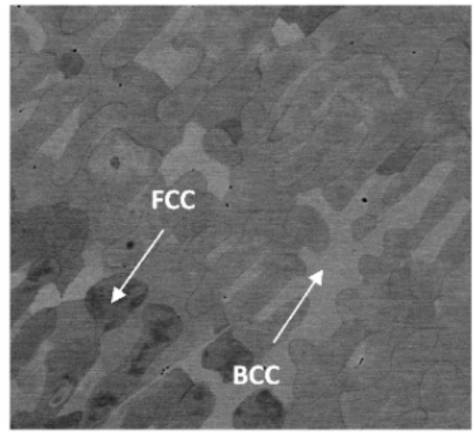

d)
$40 \mu \mathrm{m}$

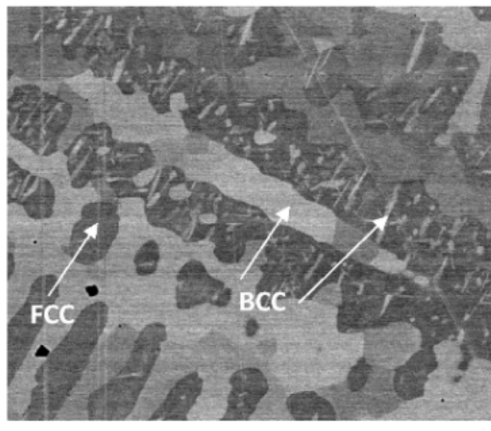

e)

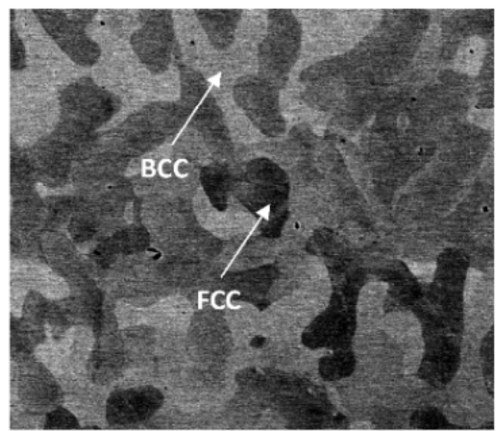

c)

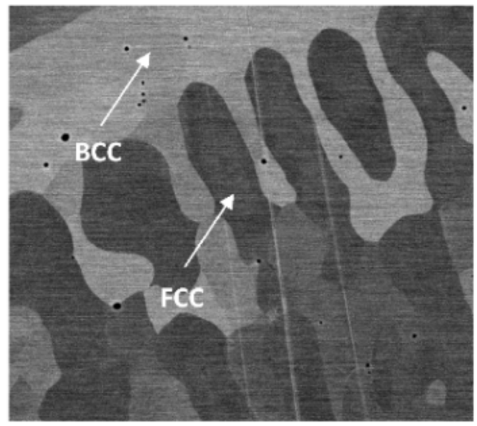

f)

Figure 2. SEM images taken on the initial (AC) state (a) and on the samples heat-treated for $1 \mathrm{~h}$ at 560 (b), 700 (c), 923 (d), 1150 (e) and $1273 \mathrm{~K}(\mathbf{f})$ and quick-cooled by water-quenching (WQ).

The images were taken by using the backscattered electrons, making the contrast by different atomic compositions of phases, showing the typical dendrite features characterizing the microstructures of the samples heat-treated at different temperatures and 
water-quenched. Similar to previously reported results $[4,5]$, the experimental results reveal a global microstructure with FCC-phase dendrite and BCC-phase inter-dendrite, as marked in the images. Typical compositions of these phases can be found in the previous works $[4,5]$. The general picture is somehow changed in the case of the sample treated at $1150 \mathrm{~K}$ (see Figure 2e), where BCC-phase needle-shaped particles were formed inside FCC regions. The formation of these particles is certainly corresponding to the exothermic peak $\mathrm{C}$ in the thermogram of Figure 1.

More detailed SEM investigations have revealed that in the case of the WQ sample aged at $923 \mathrm{~K}$, the BCC-phase regions of the sample are decomposed into small, cuboidalshaped particles having a size between 50 and $150 \mathrm{~nm}$, as presented in Figure 3. In the figure, both the lower magnification image (already shown in Figure 2d) and the higher magnification, one on the WQ sample aged at $923 \mathrm{~K}$, can be seen. This spinodal-like decomposition is certainly corresponding to the other, lower exothermic peak B in the curve of Figure 1.

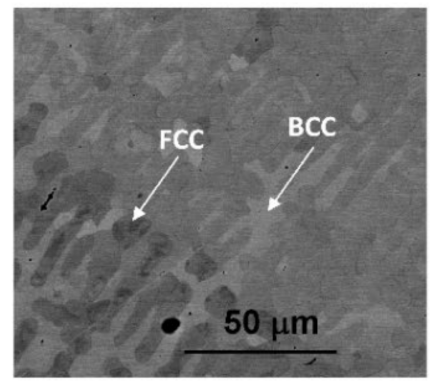

a)

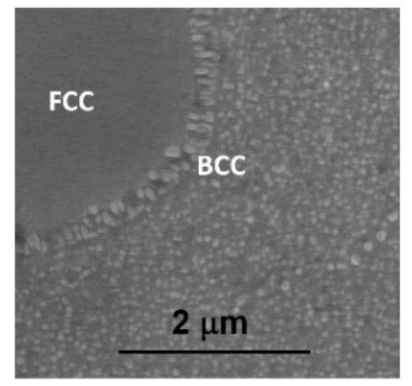

b)

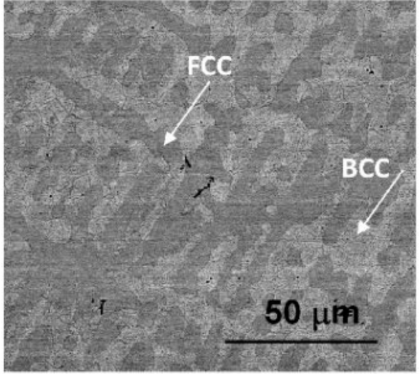

c)

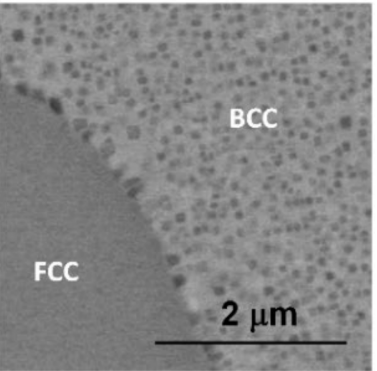

d)

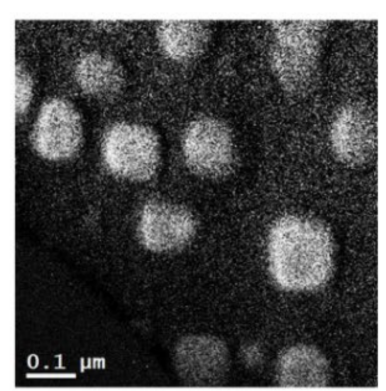

e)

Figure 3. SEM images taken on the samples heat-treated for $1 \mathrm{~h}$ at $923 \mathrm{~K}$, quick-cooled by water quenching $(\mathbf{a}, \mathbf{b})$ and at $1150 \mathrm{~K}$, but slowly cooled with the furnace $(\mathbf{c}, \mathbf{d})$. The microstructure of the later sample was also investigated by EFTEM, indicating an enhanced amount of $\mathrm{Cr}$ inside the cuboidal-shaped particles in the Cr-map (e).

Furthermore, experimental results have also shown that in the case of SC sample heat-treated at $1150 \mathrm{~K}$ and then slowly cooled with the furnace to room temperature, the resulting microstructure-also presented in Figure 3 for comparison-shows similar features to that observed in the two WQ samples aged at $1150 \mathrm{~K}$ and at $923 \mathrm{~K}$, mentioned above. Both the global view showing the mixture of FCC and BCC regions with the BCC-phase needle-shaped particles and the local spinodal-like decomposition of the BCC regions into small particles can be observed in this sample (see Figure $3 c, d$ ). Since the obtained structure has not been observed in the literature so far, further TEM and SEM investigations were performed to know as many details as possible about the particles (see later). Here we note that the results of EFTEM investigations indicate an enhanced amount of $\mathrm{Cr}$ inside the cuboidal-shaped particles (see in Figure 3e).

Figure 4 shows the XRD profiles taken on some investigated samples. The results of the XRD measurements are in good agreement with that of SEM investigation, indicating that the general structure of all heat-treated samples remains unchanged, always containing 
a mixture of FCC and BCC lattices. Without detailed analysis, it can also be seen that the XRD profiles reflect a significant difference between the microstructures of the WQ and SC samples aged at $1150 \mathrm{~K}$ but show many similarities between the structure of the SC sample and that of the WQ sample aged at $923 \mathrm{~K}$.

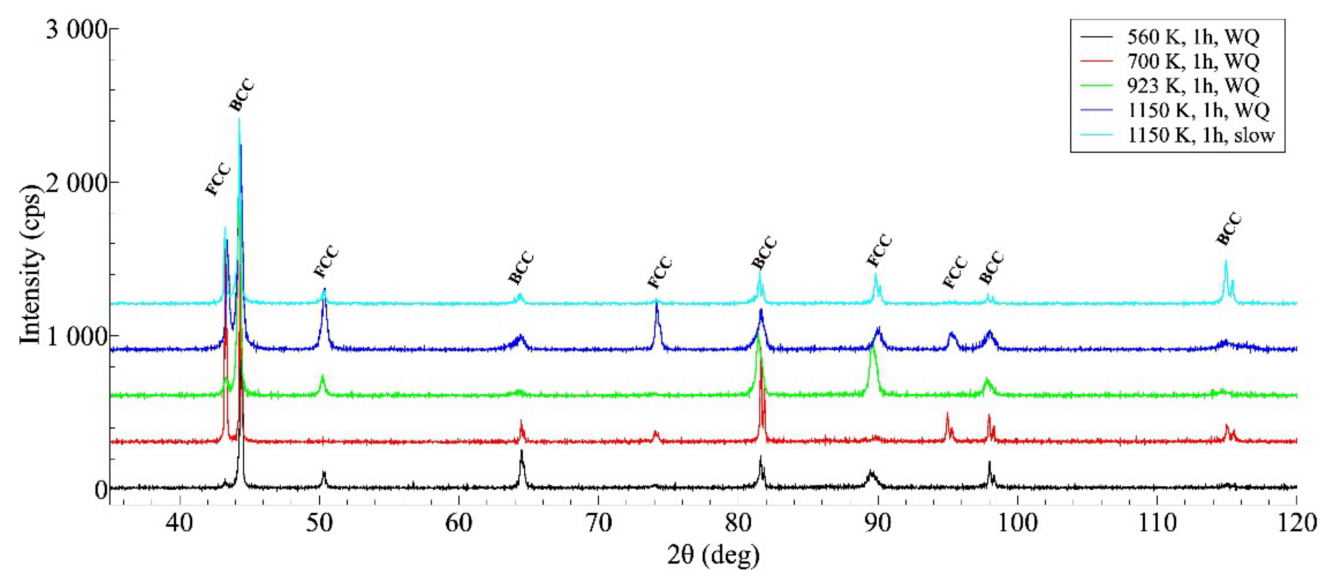

Figure 4. XRD profiles taken on the samples after different heat-treatments, showing the microstructure having face-centered cubic (FCC)/ body-centered cubic (BCC) duplex after each heat treatment (the curves are shifted vertically by about 300 units from each other for a better view).

\subsection{A Possible Sequence of Phase Transformations}

Due to their high entropy, the microstructure of HEAs would be very complicated. However, in a realistic process, when the sample is allowed to cool together with the furnace, the mentioned microstructure formed from a phase transition at about $1150 \mathrm{~K}$, in region C, followed by decomposition at about $900 \mathrm{~K}$, in region B in Figure 1 remains stable until the sample has cooled to room temperature. Accordingly, a schematic sequence of the evolution of the phase structure in $\mathrm{NiCoFeCrGa}$ high entropy alloy is suggested in Figure 5.

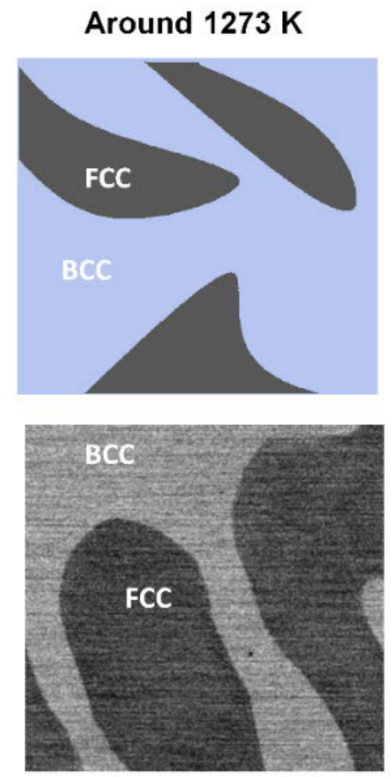

a)
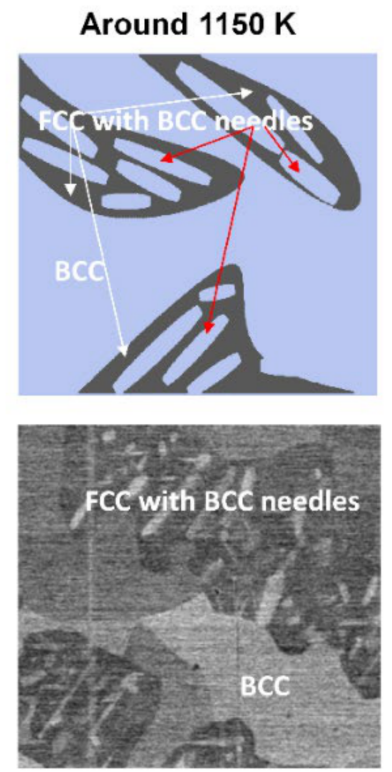

b)
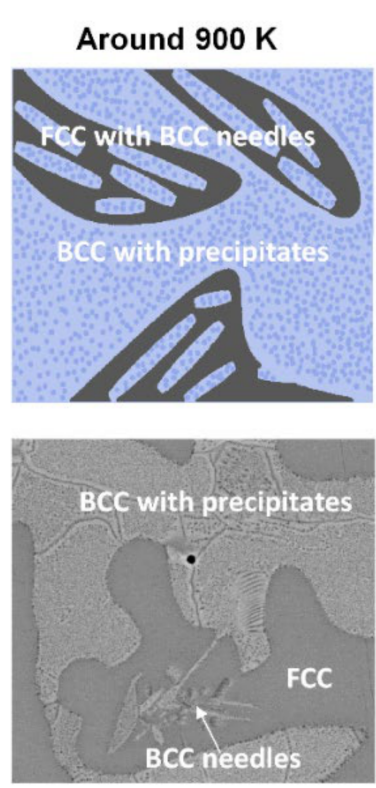

c)

Figure 5. Schematic sequence of the evolution of the phase structure during slow cooling (top row) and the corresponding SEM micrographs (bottom row) taken on the samples heat-treated under conditions of (a) $1273 \mathrm{~K}$ for $1 \mathrm{~h}$ and WQ, (b) $1150 \mathrm{~K}$ for $1 \mathrm{~h}$ and WQ and (c) $1150 \mathrm{~K}$ for $1 \mathrm{~h}$ and slowly cooling with the furnace. 
Distinctive structural and chemical changes are visible in Figure 5. In the hightemperature state, the entropic term $(T \Delta S)$ of Gibbs-equation $(\Delta G=\Delta H-T \Delta S)$ is high enough due to high-temperature (in the region $\mathrm{D}$ of the thermogram shown in Figure 1). This phenomenon plays a key role in stabilizing the near 50-50\% phase mixture of the two solid solution phases [4]. When the temperature decreases, the entropic term also lowers, so the enthalpy term $(\Delta H)$ becomes more significant in the balance due to the chemical/lattice energies. This first leads to a crystal structure change, where a significant proportion of the FCC structure undergoes a transformation to needle-like BCC structures. It is worth mentioning that the chemical composition of the BCC-phase needle-shaped particles located inside the FCC regions is similar to that of the original BCC regions formed from the high-temperature state (in the region $C$ in Figure 1) [4]. Furthermore, with lowering the temperature, a spinodal-like decomposition takes place with the formation of small cuboidal particles inside BCC regions (in the region B in Figure 1). Further investigations are needed to study in detail the whole phase-transition process. In the present case, the experimental results suggest that continuing the cooling, no more change is visible in the system; thus, the state developed around $900 \mathrm{~K}$ can be attributed to that room temperature one.

\subsection{Microstructure of the Spinodally Formed Precipitates}

Considering the microstructures of the investigated NiCoFeCr-based HEA alloys, the mixture of the relatively large FCC and BCC regions, as well as the presence of the needle-like BCC phase precipitates, are well-established. However, as mentioned, the spinodal-like decomposition of the BCC phase together with the formation of the small cuboidal particles is a new experimental observation. Hence, far, we have no knowledge of such phase-transition. This is a strong motivation for us to see in more detail both the microstructure and magnetic behavior of these small particles.

Figure 6 shows a bright-field TEM image on the BCC region containing cuboidal precipitates of the SC sample (Figure 6a) and the corresponding selected area electron diffraction (SAED) pattern (Figure 6b). The indexed SAED pattern corresponds to the BCC phase from the zone-axis $<331>$. The cuboidal precipitates do not have a different structure or orientation, as they did not cause extra spots in the diffraction pattern (although their volume fraction is high, as seen from the BF image). In addition to the bcc spot, only thermal diffuse scattering (TDS) streaks can be seen in the SAED pattern.

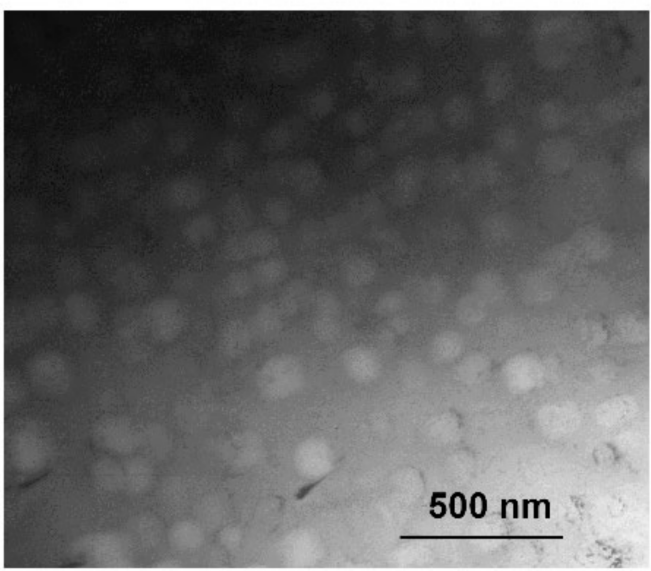

a)

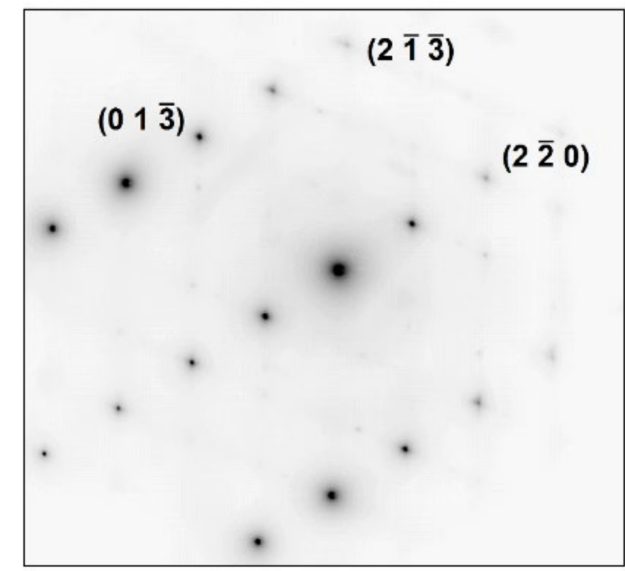

b)

Figure 6. Microstructure of the BCC region of the SC sample heat-treated at $1150 \mathrm{~K}$ for $1 \mathrm{~h}$ and slowly cooled, shown by bright-field TEM (a) and corresponding selected area electron diffraction (SAED)-pattern (b) from the zone-axis of orientation $<331>$. 
The mentioned similarity in structure and orientation of the cuboidal precipitates to the parent matrix also has been confirmed by the results of EBSD investigation, shown in Figure 7, where inverse pole figure map FCC and BCC phases can be seen.

a)

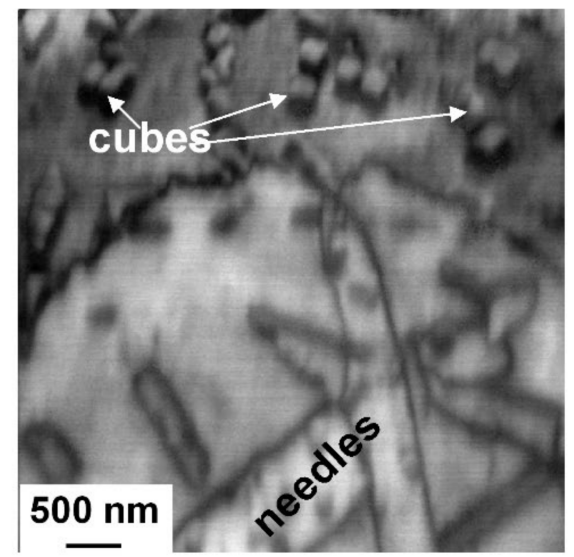

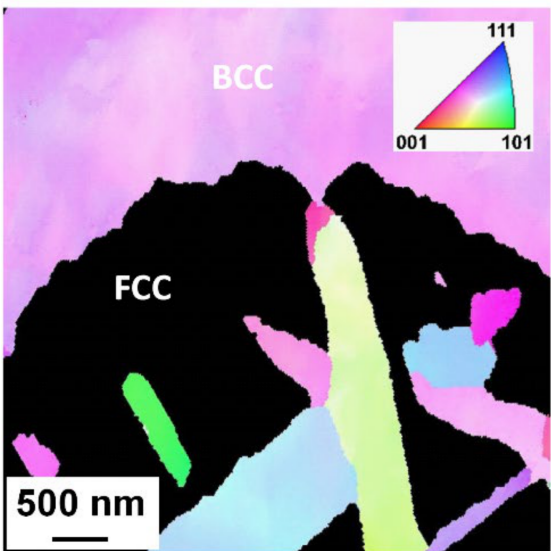

b)

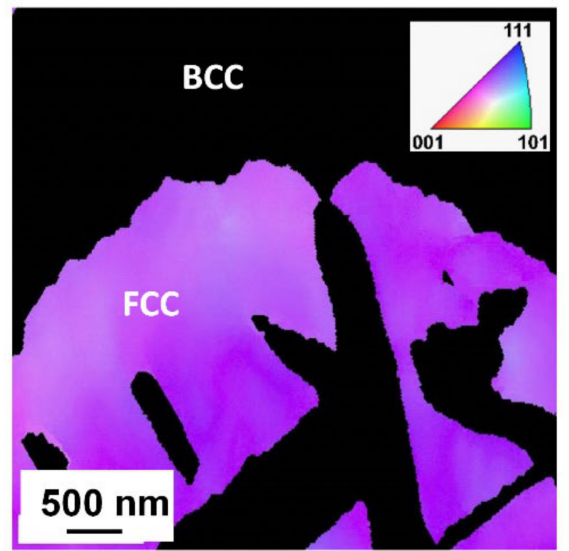

c)

Figure 7. Typical microstructure of the slowly cooled (SC) sample heat-treated at $1150 \mathrm{~K}$ for $1 \mathrm{~h}$ and slowly cooled, demonstrated by image quality plot build from electron backscattered diffraction (EBSD) data (a) and the corresponding inverse pole figure map of FCC (b) and of BCC (c) phases.

A typical microstructure-containing extended regions of FCC and BCC phases, as well as needle-like and cuboidal particles-of the microstructure of the SC sample heat-treated at $1150 \mathrm{~K}$ for $1 \mathrm{~h}$ can be seen in this figure. The BCC nature of both needleand cuboidal precipitates is well perceptible in the inverse pole figure (IPF) presentation. Furthermore, no phase boundary is observable between the cubes and the parent matrix, indicating unambiguously that these cuboidal particles are created only by segregation and/or migration of chemical elements with the possible spinodal mechanism.

The obtained results would suggest a significant difference between the composition of the cuboidal particles and the surrounding matrix.

Elemental mappings taken by TOF-SIMS on the characteristic spinodal-like decomposition are shown in Figure 8. Significantly increased ${ }^{52} \mathrm{Cr}$ ion content is detected in the small cuboid precipitates. This is in good agreement with the result of the EFTEM measurement shown in Figure 3e. Along with the local increment of $\mathrm{Cr}$, the decrease of the other components can be observed when looking at the cuboids. At the same time, the $\mathrm{BCC}$ matrix has a higher concentration of all other ${ }^{56} \mathrm{Fe},{ }^{58} \mathrm{Ni},{ }^{59} \mathrm{Co}$ and ${ }^{69} \mathrm{Ga}$ ions, while ${ }^{52} \mathrm{Cr}$ ion depletion is evident in the same area. Interestingly, differences between the FCC and BCC matrix can also be seen in Figure 8. The concentration of ${ }^{56} \mathrm{Fe}$ ions seems to be 
less affected by the phase boundary than ${ }^{58} \mathrm{Ni},{ }^{59} \mathrm{Co}$ and ${ }^{69} \mathrm{Ga}$ ions, where a decrease in the FCC phase appears.
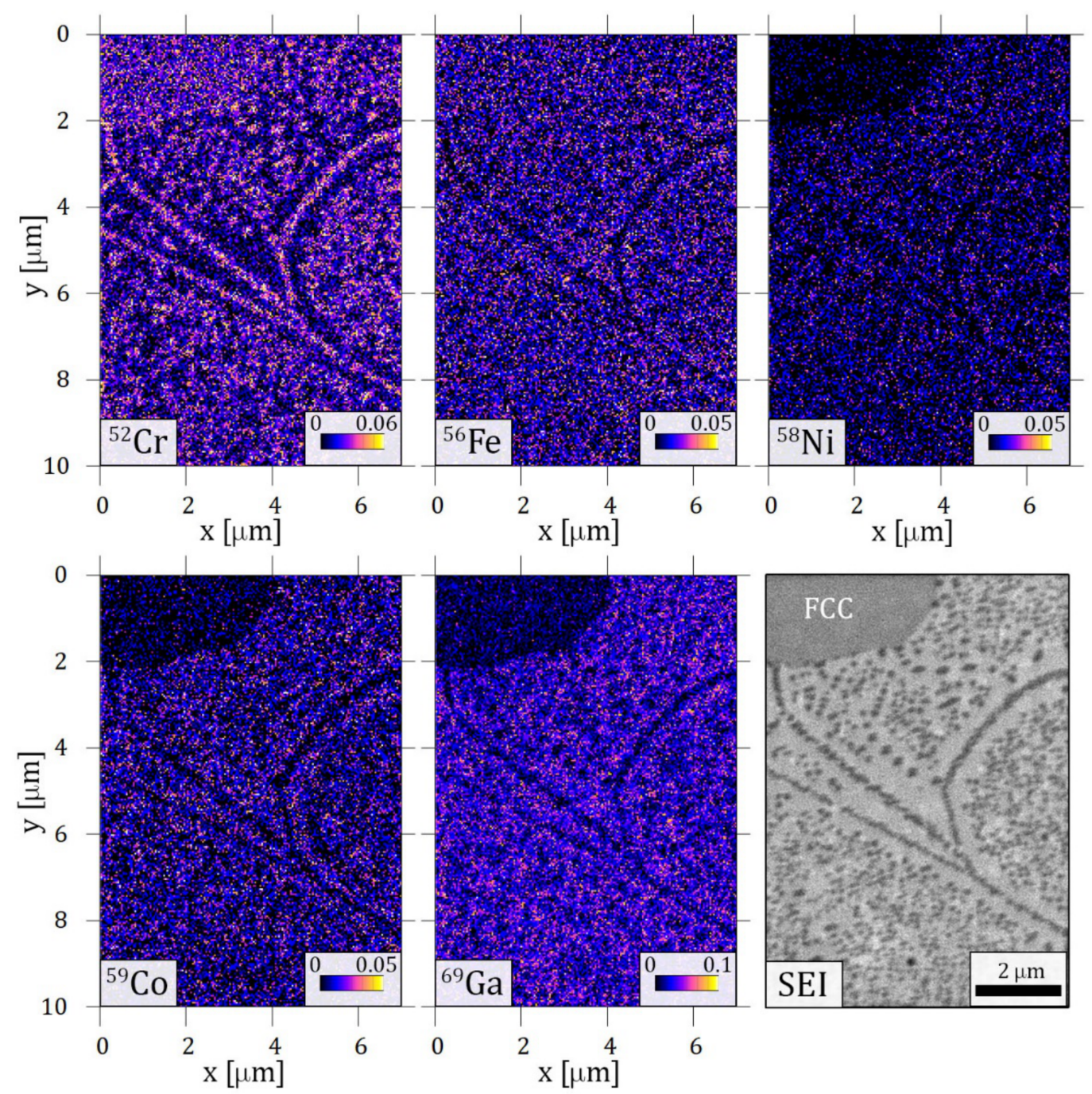

Figure 8. Elemental maps built from time-of-flight secondary ion mass spectroscopy (TOF-SIMS) results of the sample heat-treated at $1150 \mathrm{~K}$ for $1 \mathrm{~h}$ and slowly cooled. The area contains a phase boundary of BCC with cuboid structure and FCC phase (marked on the secondary electron image, SEI).

Considering the quantitative comparison, Figure 9 shows the typical ES results of elemental analysis for both the cubes and the matrix. The chemical composition of two cubes and of two local surrounding BCC matrix-areas is shown in Figure 9a. It can be seen that besides the decrease of $\mathrm{Ni}$, there is a significant-up to $40 \%$-increase of $\mathrm{Cr}$ concentration in the cubes. For completeness, the composition of the FCC phase is also shown in Figure $9 \mathrm{~b}$. Here we note that as the ES measurements are carried out to determine the chemical composition near the surface, the obtained concentration of Ga is systematically lower than the nominal value. This is presumably due to the fact that Ga is a low melting point metal (its melting point is only $30^{\circ} \mathrm{C}$ ), and due to its partial surface evaporation-during measurement- the detectable amount will be less than the expected one. In any case, the increased amount of $\mathrm{Cr}$ within the cubes is a proven fact. 


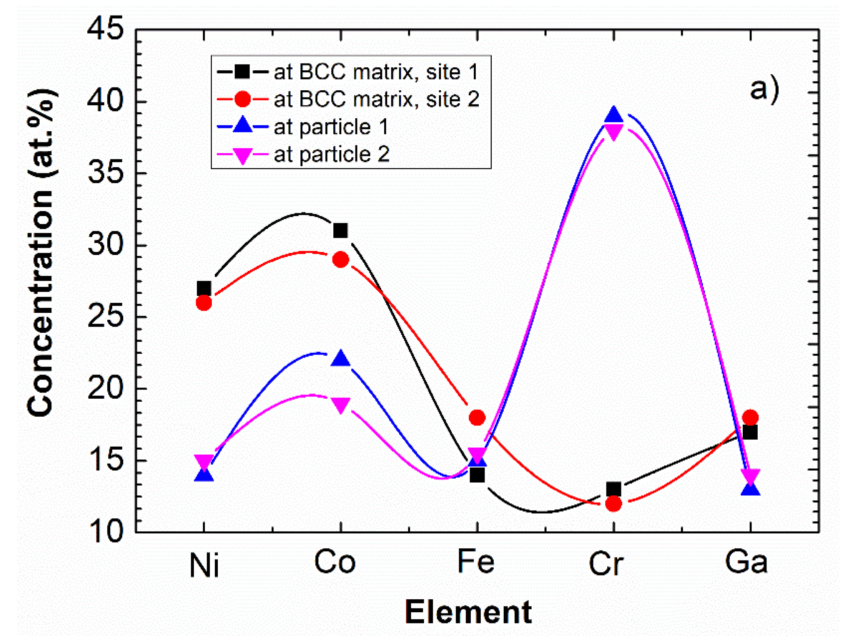

(a)

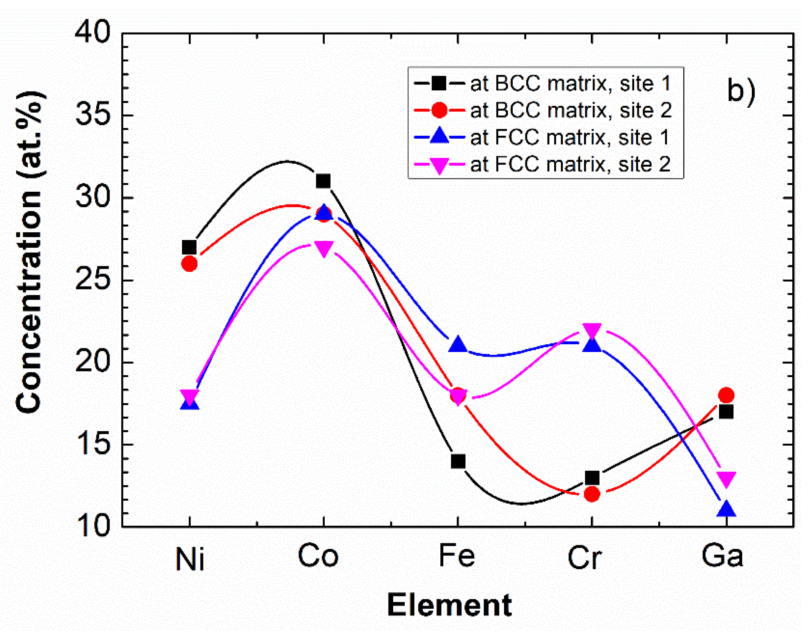

(b)

Figure 9. Composition of cuboidal particles and the surrounding BCC matrix (a), as well as that of BCC matrix and FCC phase (b). The data determined by ES having a relative error of about $5 \%$. Note that the connecting lines are only indicating the elements belonging to the same measured points for easier clarity.

Figure 10 presents the AFM and MFM images taken on the same slowly cooled sample, showing all four main features-FCC, BCC regions, BCC-phase needle-shaped precipitates and cuboidal particles - of the microstructure of this sample. Results of the magnetic measurements reveal that despite the magnetic behavior of BCC-phase in general, the cuboidal particles behave like non-magnetic islets due to the high $\mathrm{Cr}$ content inside the BCC-phase regions. Although further studies are needed, it can be seen that the formation of small particles can determine not only the mechanical but also the magnetic properties of the material, broadening the potential applications of high entropy alloys.

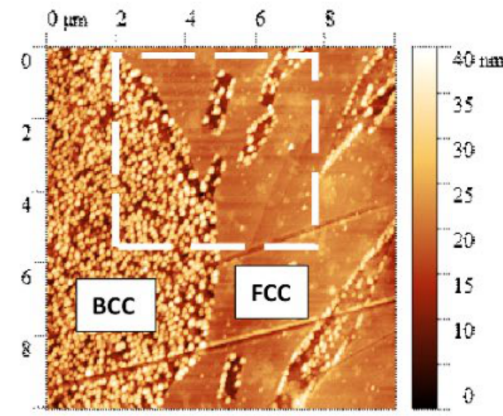

a)

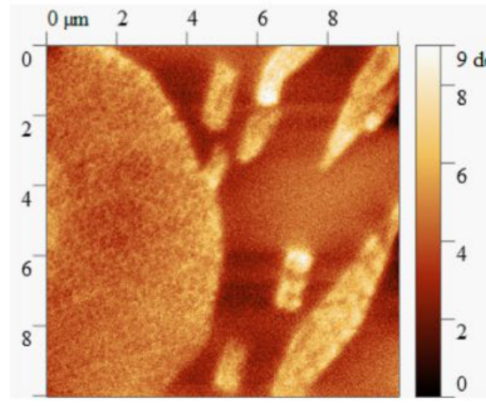

d)

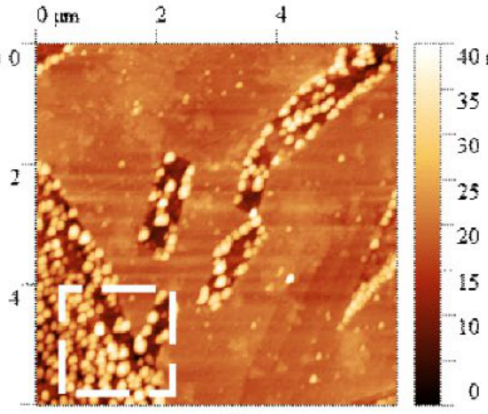

b)

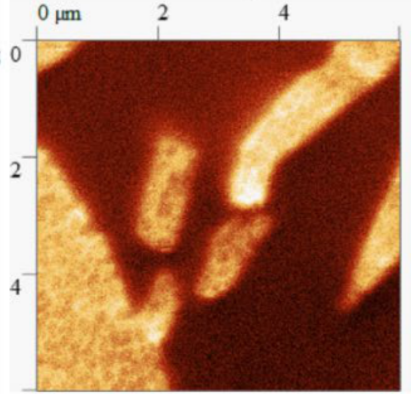

e)

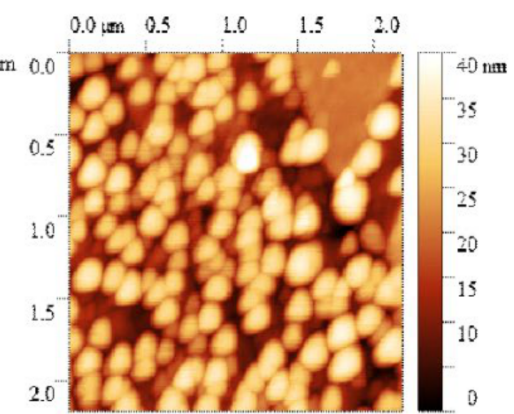

c)

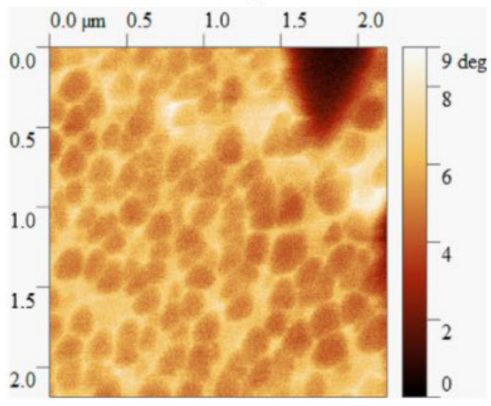

f)

Figure 10. AFM $(\mathbf{a}-\mathbf{c})$ and corresponding MFM images (d-f) taken at different magnifications on the microstructure of the sample heat-treated at $1150 \mathrm{~K}$ for $1 \mathrm{~h}$ and slowly cooled. On the MFM image, the brighter color represents the higher magnetic property. Despite the magnetic behavior of the BCC phase, the cuboidal particles behave like non-magnetic regions due to the high $\mathrm{Cr}$ content. 
As mentioned before, due to their high entropy, the microstructure of HEAs would be very complicated. Although at this moment, no thermodynamic calculation is available to rationalize the suggested sequence of phase transformations, the obtained results will hopefully provide important experimental experiences to better understand several behaviors of HEAs, such as the mechanical, the corrosive properties and even the diffusion behavior of the individual elements.

\section{Conclusions}

Phase transitions in the NiCoFeCrGa HEA were studied by completing different heattreatments and investigating the microstructure using several methods. According to the experimental results, a sequence of the phase transitions can be established, describing the main steps of a realistic process when freely cooling the sample with the furnace from high to room temperature. At high temperatures higher than $1200 \mathrm{~K}$, both FCC and BCC solid solution phases are presented in equal fractions in the material. Lowering the temperature to around $1100 \mathrm{~K}$, BCC-phase needle-shaped precipitates are formed in FCC regions. Going down to around $900 \mathrm{~K}$, a spinodal-like decomposition takes place with the formation of $\mathrm{Cr}$ rich, small-size cuboidal particles, which may determine both the mechanical and magnetic behaviors of the material, broadening the potential applications of high entropy alloys.

Author Contributions: Conceptualization, Á.V., L.K.V. and N.Q.C.; methodology, Á.V., J.L., Z.D., Z.M., D.M., L.K.V., S.K., M.W. and G.H.; validation, Á.V., L.K.V. and N.Q.C.; formal analysis, Á.V., S.K., M.W., J.L., Z.D., Z.M., D.M. and G.H.; resources, Á.V., M.W. and S.K.; writing-original draft preparation, Á.V. and N.Q.C.; writing—review and editing, Á.V., M.W., S.K., G.H. and N.Q.C.; supervision, Á.V. and N.Q.C. All authors have read and agreed to the published version of the manuscript.

Funding: This research received no external funding.

Institutional Review Board Statement: Not applicable.

Informed Consent Statement: Not applicable.

Data Availability Statement: The data that support the findings of this study are all own results of the authors, not available anywhere.

Acknowledgments: This work was completed in the ELTE Institutional Excellence Program (TKP2020IKA-05) financed by the Hungarian Ministry of Human Capacities. The work was also supported by the research infrastructure of the Bay Zoltán Institute. The research of S.K. was supported by the EMPAPOSTDOCS-II program as part of the European Union Horizon 2020 research and innovation program under the Marie Sklodowska-Curie grant agreement number 754364. Research of N.Q.C. and L.K.V. was also supported by the Hungarian-Russian Research Program No. 2017-2.3.4-TÉT-RU2017-00005 and the Hungarian Scientific Research Fund (OTKA) Grant No. K128229. The authors would like to thank Johann Michler (Empa Thun) for the fruitful discussions on TOF-SIMS analysis.

Conflicts of Interest: The authors declare no conflict of interest.

\section{References}

1. Pickering, E.J.; Jones, N.G. High-Entropy Alloys: A Critical Assessment of Their Founding Principles and Future Prospects. Int. Mater. Rev. 2016, 61, 183-202. [CrossRef]

2. Schuh, B.; Mendez-Martin, F.; Völker, B.; George, E.P.; Clemens, H.; Pippan, R.; Hohenwarter, A. Mechanical Properties, Microstructure and Thermal Stability of a Nanocrystalline CoCrFeMnNi High-Entropy Alloy after Severe Plastic Deformation. Acta Mater. 2015, 53, 174-184. [CrossRef]

3. Pickering, E.J.; Muñoz-Moreno, R.; Stone, H.J.; Jones, N.G. Precipitation in the Equiatomic High-Entropy Alloy CrMnFeCoNi. Scr. Mater. 2016, 111, 106-109. [CrossRef]

4. Vida, Á.; Maksa, Z.; Molnár, D.; Huang, S.; Kovac, J.; Varga, L.K.; Vitos, L.; Chinh, N.Q. Evolution of the Phase Structure after Different Heat Treatments in NiCoFeCrGa High Entropy Alloy. J. Alloys Compd. 2018, 743, 234-239. [CrossRef]

5. Molnár, D.; Vida, Á.; Huang, S.; Chinh, N.Q. The Effect of Cooling Rate on the Microstructure and Mechanical Properties of NiCoFeCrGa High-Entropy Alloy. J. Mater. Sci. 2018, 54, 5074-5082. [CrossRef]

6. Yeh, J.W.; Chen, S.K.; Gan, J.Y.; Lin, S.J.; Chin, T.S.; Shun, T.T.; Tsau, C.H.; Chang, S.Y. Formation of Simple Crystal Structures in Cu-Co-Ni-Cr-Al-Fe-Ti-V Alloys with Multiprincipal Metallic Elements. Metall. Mater. Trans. A Phys. Metall. Mater. Sci. 2004, 35, 2533-2536. [CrossRef] 
7. Yeh, J.W.; Chen, S.K.; Lin, S.J.; Gan, J.Y.; Chin, T.S.; Shun, T.T.; Tsau, C.H.; Chang, S.Y. Nanostructured High-Entropy Alloys with Multiple Principal Elements: Novel Alloy Design Concepts and Outcomes. Adv. Eng. Mater. 2004, 6, 299-303. [CrossRef]

8. Yeh, J.W. Recent Progress in High-Entropy Alloys. Ann. Chim. Sci. Des. Mater. 2006, 31, 633-648. [CrossRef]

9. Praveen, S.; Murty, B.S.; Kottada, R.S. Alloying Behavior in Multi-Component AlCoCrCuFe and NiCoCrCuFe High Entropy Alloys. Mater. Sci. Eng. A 2012, 534, 83-89. [CrossRef]

10. Tasan, C.C.; Deng, Y.; Pradeep, K.G.; Yao, M.J.; Springer, H.; Raabe, D. Composition Dependence of Phase Stability, Deformation Mechanisms, and Mechanical Properties of the CoCrFeMnNi High-Entropy Alloy System. JOM 2014, 66, 1993-2001. [CrossRef]

11. Otto, F.; Dlouhý, A.; Somsen, C.; Bei, H.; Eggeler, G.; George, E.P. The Influences of Temperature and Microstructure on the Tensile Properties of a CoCrFeMnNi High-Entropy Alloy. Acta Mater. 2013, 61, 5743-5755. [CrossRef]

12. Singh, A.K.; Subramaniam, A. On the Formation of Disordered Solid Solutions in Multi-Component Alloys. J. Alloys Compd. 2014, 587, 113-119. [CrossRef]

13. Jones, N.G.; Aveson, J.W.; Bhowmik, A.; Conduit, B.D.; Stone, H.J. On the Entropic Stabilisation of an Al0.5CrFeCoNiCu High Entropy Alloy. Intermetallics 2014, 54, 148-153. [CrossRef]

14. Ye, Y.F.; Wang, Q.; Lu, J.; Liu, C.T.; Yang, Y. High-Entropy Alloy: Challenges and Prospects. Mater. Today 2016, 19, 349-362. [CrossRef]

15. Ma, D.; Yao, M.; Pradeep, K.G.; Tasan, C.C.; Springer, H.; Raabe, D. Phase Stability of Non-Equiatomic CoCrFeMnNi High Entropy Alloys. Acta Mater. 2015, 98, 288-296. [CrossRef]

16. Senkov, O.N.; Miller, J.D.; Miracle, D.B.; Woodward, C. Accelerated Exploration of Multi-Principal Element Alloys with Solid Solution Phases. Nat. Commun. 2015, 6, 6529. [CrossRef]

17. Senkov, O.N.; Miller, J.D.; Miracle, D.B.; Woodward, C. Accelerated Exploration of Multi-Principal Element Alloys for Structural Applications. Calphad Comput. Coupling Phase Diagr. Thermochem. 2015, 50, 32-48. [CrossRef]

18. Lucas, M.S.; Wilks, G.B.; Mauger, L.; Muñoz, J.A.; Senkov, O.N.; Michel, E.; Horwath, J.; Semiatin, S.L.; Stone, M.B.; Abernathy, D.L.; et al. Absence of Long-Range Chemical Ordering in Equimolar FeCoCrNi. Appl. Phys. Lett. 2012, 100, 251907. [CrossRef]

19. Ang, A.S.M.; Berndt, C.C.; Sesso, M.L.; Anupam, A.; Praveen, S.; Kottada, R.S.; Murty, B.S. Plasma-Sprayed High Entropy Alloys: Microstructure and Properties of AlCoCrFeNi and MnCoCrFeNi. Metall. Mater. Trans. A Phys. Metall. Mater. Sci. 2015, 46, 791-800. [CrossRef]

20. Chernenko, V.A.; Pons, J.; Cesari, E.; Zasimchuk, I.K. Transformation Behaviour and Martensite Stabilization in the Ferromagnetic Co-Ni-Ga Heusler Alloy. Scr. Mater. 2004, 50, 225-229. [CrossRef]

21. Wang, Y.P.; Li, B.S.; Ren, M.X.; Yang, C.; Fu, H.Z. Microstructure and Compressive Properties of AlCrFeCoNi High Entropy Alloy. Mater. Sci. Eng. A 2008, 491, 154-158. [CrossRef]

22. Chou, H.P.; Chang, Y.S.; Chen, S.K.; Yeh, J.W. Microstructure, Thermophysical and Electrical Properties in AlxCoCrFeNi $(0 \leq x$ 52) High-Entropy Alloys. Mater. Sci. Eng. B Solid-State Mater. Adv. Technol. 2009, 163, 184-189. [CrossRef]

23. Jiao, Z.M.; Chu, M.Y.; Yang, H.J.; Wang, Z.H.; Qiao, J.W. Nanoindentation Characterised Plastic Deformation of a Al0.5CoCrFeNi High Entropy Alloy. Mater. Sci. Technol. 2015, 31, 1244-1249. [CrossRef]

24. Wang, W.R.; Wang, W.L.; Wang, S.C.; Tsai, Y.C.; Lai, C.H.; Yeh, J.W. Effects of Al Addition on the Microstructure and Mechanical Property of Al XCoCrFeNi High-Entropy Alloys. Intermetallics 2012, 26, 44-51. [CrossRef]

25. Shun, T.T.; Hung, C.H.; Lee, C.F. Formation of Ordered/Disordered Nanoparticles in FCC High Entropy Alloys. J. Alloys Compd. 2010, 493, 105-109. [CrossRef]

26. Vida, A.; Varga, L.K.; Chinh, N.Q.; Molnar, D.; Huang, S.; Vitos, L. Effects of the Sp Element Additions on the Microstructure and Mechanical Properties of NiCoFeCr Based High Entropy Alloys. Mater. Sci. Eng. A 2016, 669, 14-19. [CrossRef]

27. Huang, S.; Vida, Á.; Li, W.; Molnár, D.; Kyun Kwon, S.; Holmström, E.; Varga, B.; Károly Varga, L.; Vitos, L. Thermal Expansion in FeCrCoNiGa High-Entropy Alloy from Theory and Experiment. Appl. Phys. Lett. 2017, 110, 241902. [CrossRef]

28. Dunn, D.N.; Hull, R. Reconstruction of Three-Dimensional Chemistry and Geometry Using Focused Ion Beam Microscopy. Appl. Phys. Lett. 1999, 75, 3414. [CrossRef]

29. Giannuzzi, L.A.; Stevie, F.A. Introduction to Focused Ion Beams: Instrumentation, Theory, Techniques and Practice; Springer Science \& Business Media: Berlin/Heidelberg, Germany, 2005; ISBN 0387231161.

30. Giannuzzi, L.A.; Utlaut, M. Non-Monotonic Material Contrast in Scanning Ion and Scanning Electron Images. Ultramicroscopy 2011, 111, 1564-1573. [CrossRef] [PubMed]

31. Pillatsch, L.; Östlund, F.; Michler, J. FIBSIMS: A Review of Secondary Ion Mass Spectrometry for Analytical Dual Beam Focussed Ion Beam Instruments. Prog. Cryst. Growth Charact. Mater. 2019, 65, 1-19. [CrossRef]

32. Priebe, A.; Utke, I.; Pethö, L.; Michler, J. Application of a Gas-Injection System during the FIB-TOF-SIMS Analysis-Influence of Water Vapor and Fluorine Gas on Secondary Ion Signals and Sputtering Rates. Anal. Chem. 2019, 91, 11712-11722. [CrossRef] [PubMed]

33. Pillatsch, L.; Kalácska, S.; Maeder, X.; Michler, J. In Situ Atomic Force Microscopy Depth-Corrected Three-Dimensional Focused Ion Beam Based Time-of-Flight Secondary Ion Mass Spectroscopy: Spatial Resolution, Surface Roughness, Oxidation. Microsc. Microanal. 2020. [CrossRef]

34. Nelson, J.B.; Riley, D.P. An Experimental Investigation of Extrapolation Methods in the Derivation of Accurate Unit-Cell Dimensions of Crystals. Proc. Phys. Soc. 1945, 57, 160-177. [CrossRef] 